\title{
Evaluating comorbidities in total hip and knee arthroplasty: available instruments
}

\author{
Kristian Bjorgul • Wendy M. Novicoff • \\ Khaled J. Saleh
}

Received: 18 March 2010/Accepted: 19 October 2010/Published online: 13 November 2010

(C) The Author(s) 2010. This article is published with open access at Springerlink.com

\begin{abstract}
Each year millions of patients are treated for joint pain with total joint arthroplasty, and the numbers are expected to rise. Comorbid disease is known to influence the outcome of total joint arthroplasty, and its documentation is therefore of utmost importance in clinical evaluation of the individual patient as well as in research. In this paper, we examine the various methods for obtaining and assessing comorbidity information for patients undergoing joint replacement. Multiple instruments are reliable and validated for this purpose, such as the Charlson Index, Index of Coexistent Disease, and the Functional Comorbidity Index. In orthopedic studies, the Charnley classification and the American Society of Anesthesiologists physical function score (ASA) are widely used. We recommend that a well-documented comorbidity index that incorporates some aspect of mental health is used along with other appropriate instruments to objectively assess the preoperative status of the patient.
\end{abstract}

\footnotetext{
K. Bjorgul ( $\bowtie)$

Orthopaedic Department, Ostfold Hospital Trust,

1603 Fredrikstad, Norway

e-mail: krisbjorgul@gmail.com

W. M. Novicoff

Department of Orthopaedic Surgery,

University of Virginia Health System, PO Box 800159 ,

Charlottesville, VA 22908-0159, USA

e-mail:wmn2v@virginia.edu

\section{K. J. Saleh}

School of Medicine, Department of Surgery,

Southern Illinois University, P.O. Box 19679,

Springfield, IL 62794-9679, USA

e-mail: ksaleh@siumed.edu
}

Keywords Hip · Knee - Replacement - Comorbidity · ASA · Joint

\section{Introduction}

Each year, joint pain from multiple causes decreases the quality of life of millions of patients [1]. Total joint arthroplasty remains one of the most commonly performed and universally successful operative interventions for patients with osteoarthritis and other joint problems, with over 600,000 total knee procedures and nearly 300,000 total hip procedures performed in 2007 [2]. The rapid increase in joint surgeries each year can be attributed to the rising population age of the country and the increasing prevalence of arthritis and other factors that lead to the need for these procedures [3]. In addition, the perceived and real success of total joint arthroplasty-improved functional status, pain relief, low perioperative morbidity and mortality, and good implant survivorship - has expanded demand among all population segments [4].

Comorbidities are defined as diseases or medical conditions unrelated in etiology or causality to the principal diagnosis that coexist with the disease of interest. It is important to identify the comorbidities of the patient, because they may delay diagnosis, alter treatment, lead to complications, influence survival, and confound analysis of outcomes [5]. There is ample evidence that comorbidity is a major factor in determining the outcomes of various conditions, and there is a large body of literature discussing the multiple aspects of comorbidity. The general finding is a close relationship between comorbidities and complications [6], mortality [7], functional outcome [8], and consumption of healthcare resources $[9,10]$. 
Total joint replacement generally improves health-related quality of life, but when improvement is modest, the role of comorbidities is often highlighted [11, 12]. Since the prevalence of comorbidities increases with advancing age, with estimates ranging from $60 \%$ to $88 \%$ of the population aged 65 years and above having at least one comorbidity [9], it is expected that a significant proportion of arthroplasty patients have comorbidities [13]. It is clear, however, that the rate of comorbidities is different for hip replacement patients compared with knee replacement patients, with hip replacement patients generally having lower rates of comorbidities.

Although it is generally known that mortality is quite low following total joint replacement, studies have found that the presence of comorbidities can increase the chance of mortality [14, 15]. Kreder et al. found that mortality increased 24 times in the presence of comorbidities compared with patients with no comorbidities.

\section{Collecting data on comorbidities}

Data pertaining to comorbidities might be collected by directly interviewing the patient, by patient self-reporting, reviewing medical charts or by extraction from databases [7, 16]. It is generally believed that administrative data, such as data submitted for insurance claims and billing purposes, generally agree with patient chart data for recording of comorbidities, but there is evidence that comorbidities are underreported in administrative data, especially in terms of specificity of prior events such as myocardial infarction [17, 18]. Since most administrative data rely on discharge diagnoses, accurate documentation and subsequent coding of diagnoses are critical. There might be inaccuracies in coding depending on whether the coding is done by a dedicated coding team and whether or not orthopedic surgeons are part of this team $[19,20]$. One potential pitfall when studying discharge diagnoses as the primary means for identifying patient medical history is the fact that complications and their sequelae may be mistaken for comorbidities [21]. A complication refers to a condition that arises secondarily to the main diagnoses and may be related to the diagnosis or the treatment, whereas comorbidity is a preexisting condition that may modulate the outcome of treatment. This becomes an important distinction in risk adjustment and other statistical models that attempt to stratify patients based on risk of mortality or severity of illness [21].

Patient self-reporting is an attractive alternative to chart review and discharge diagnosis, since the patient is the primary source of information. Research has shown that patients can accurately and reliably report their medical conditions [22-24]. Several specific instruments have been developed to assist the patient in objectively recording their medical history. Greenfield and his colleagues developed the Self-Administered Comorbidity Questionnaire, which uses patients' reports of symptoms and conditions, as well as patients' ratings of symptom intensity to characterize total disease burden without depending on a current diagnosis [23]. This questionnaire uses closed-end questions specific to organ system or disease group and has been shown to have modest correlation with widely used medical-record-based comorbidity instruments [25].

Available comorbidity instruments

In an increasingly competitive environment, clinical outcomes assessment of healthcare providers is an important issue. When adjusting for differences in demographic and clinical risk factors among patients treated across providers, it is vital to use a validated and reliable tool. To that end, clinical quality indicators including comorbidities have been developed [21, 26].

A comorbidity index is an instrument that condenses the patient's comorbidities into a single, numeric score. It is derived from the number of coexistent diseases as well as their individual severity and allows comparisons with scores from other patients. A comorbidity index is a research tool used to stratify patients of similar risk, or allow for adjustment of varying risk, and they are thought to be too imprecise to replace clinical judgment for a specific patient [27]. Even so, some studies acknowledge the need for accounting for comorbidities, but elect not to use a formal instrument, merely counting each patient's additional diagnoses [28, 29].

In a review on methods to measure comorbidity, de Groot et al. [30] found four instruments to be sufficiently valid and reliable, of which only the Charlson Index and the Index of Coexistent Disease (ICED) have reached some recognition in the orthopedic literature $[31,32]$.

\section{The Charlson Index}

The Charlson Index was developed to quantify the influence of comorbidities on survival [31]. There are 19 defined comorbid conditions, which were selected based on their observed association with a 1-year mortality risk in a cohort of hospitalized patients in one New England hospital in 1984. Each comorbid disease is assigned a weight from 1 to 6 , and the index is the sum of the weights for each comorbid condition and can range from 0 to 33 . It has been widely used in large studies based on administrative data to predict functional outcome [33], implant survival [34], mortality [35], and length of hospital stay and resource use $[7,16]$. The reliability has been shown to be 
excellent [36], and several studies confirm that it is valid [30]. The Charlson Index might be a poor predictor of quality-of-life outcomes in patients undergoing primary hip and knee replacement, and it has been found to be less responsive than other measures of comorbidities, possibly because it is more sensitive to life-threatening conditions than to functional outcomes [37, 38]. A questionnaire version of the Charlson Index was found to be reproducible and valid, and it offers practical advantages over medicalrecord-based questionnaires [24].

\section{Index of Coexistent Disease (ICED)}

The Index of Coexistent Disease (ICED) is an index that specifically controls for comorbidity when the outcome is functional status [9, 30, 39]. It was developed based on the variations in length of stay and outcome of six medical and surgical conditions, one of which was total hip replacement [40]. The ICED consists of two different dimensions. One measures the disease severity of 14 categories of comorbid diseases, and the other measures the overall functional severity (disability). Scores are based on a list of symptoms, signs, and laboratory tests and are summarized into a four-point scale, from 0 to 3 . Though its validity and reliability were deemed good [30], we have not found the ICED to be very prevalent in the orthopedic literature. We have identified 17 articles in which ICED is a comorbidity instrument. Two articles deal with arthritis and one with total hip replacement.

\section{The Functional Comorbidity Index}

The Functional Comorbidity Index (FCI) was developed with physical function as the only outcome of interest [41]. Functional outcome generally is more interesting than mortality in orthopedic research, and a comorbidity index that could explain variation in physical outcome would be valuable to orthopedic surgeons. The FCI consists of a list of 18 diagnoses that were found to be significantly associated with declining function. One point is assigned to each diagnosis, and the points are summarized, giving the patient a score between 0 and 18. In developing the scale, the authors attempted to apply weight to the diseases after having identified their relative association with physical function. Interestingly, the weighted scores did not perform better than the nonweighted scores, indicating that a simple count of diagnoses is sufficient. The FCI has been shown to perform better than the Charlson Index when physical function was the outcome [42], but to our knowledge it has not been used in orthopedic research. The FCI includes mental health as well as obesity among the comorbidities that make up the index.
The Charnley classification

The Charnley classification is commonly used in the orthopedic literature, even though it cannot be regarded as a comorbidity index proper. It stratifies patients into three categories in order to gain better understanding of the variability in outcome, which was quantified as walking ability [43, 44]. Patients are assigned to class A if they have single joint arthropathy and no significant medical comorbidity. Class B patients have one other joint in need of an arthroplasty, or an unsuccessful or failing arthroplasty in another joint, while class $\mathrm{C}$ patients have multiple joints in need of arthroplasty, multiple failing arthoplasties or significant medical or psychological impairment. It has been suggested that category B should be dichotomized into B1 and B2 according to whether the contralateral hip has been successfully treated with an arthroplasty (B2) or remains untreated (B1) [8, 45].

The Charnley class of the patient influences the outcome as measured by Short Form-36 (SF-36) [46], Harris Hip Score $[47,48]$ as well as the Nottingham Health Profile Score [49] and the Western Ontario and McMaster Universities Osteoarthritis Index (WOMAC) [48]. Charnley class also significantly affects the function, pain, and range of motion subscales of the Harris Hip Score [47]. Furthermore, progressive deterioration in walking capacity with time has been noted, and this deterioration was also most pronounced for Charnley category C patients [47].

The distribution of patients in the Charnley classification varies over time as patients develop new comorbidities or preexistent comorbidities worsen [47]. When the Charnley scale was used as a patient-administered questionnaire for a 6-year follow-up, $52 \%$ of respondents placed themselves in Charnley category C [50].

The crucial point in the Charnley classification is how to determine whether a comorbid illness is significant or not. An illness that significantly impairs the patient's ability to walk should cause the patient to be placed in category C. This leaves it to the physician to decide whether various diseases are significant or not. A disease such as diabetes mellitus, which is known to influence outcome in several ways, might not lead to the patient being placed in Charnley class $\mathrm{C}$ if the patient is fit and manages the disease well. Thus, there is a question of whether this classification system is liable to suffer from interobserver variability to a larger extent than other systems. We are not aware of any study that has investigated the interobserver reliability of the Charnley classification.

The Charnley classification may also be used to assess levels of activity [51], which is in accordance with the authors' original intention [43]. Loosening of arthroplasty components has been shown to be more frequent in Charnley group A than group B, and group C patients, 
presumably because the classification directly relates to levels of activity [52].

Since the Charnley classification relies on an assessment of the severity of the associated conditions, it might not be suitable in studies based on chart reviews or extraction of medical records.

Dunbar et al. modified the Charnley classification instrument for use as a questionnaire to assess comorbidities in knee replacement surgery [8]. Originally designed as a physician-based instrument to assess degree of impairment in locomotion, it might be regarded as an organspecific comorbidity instrument. The authors did not compare the modified instrument with other comorbidity indices, but found that clinical outcomes varied significantly with comorbidity levels.

The Charnley classification has been modified for use with knee arthroplasty patients [8]. This study showed that Charnley class significantly affected outcomes in SF-36, WOMAC, Oxford Knee Score, and a Global Knee Score [8]. This finding is in accordance with other studies that showed that two or more comorbidities significantly correlated with decreasing knee scores [29]. In the Knee Society rating scale, patients are similarly categorized into three groups based on the same criteria. However, this scale admits patients with successfully operated contralateral knees into class A [53].

The American Society of Anesthesiologists physical status classification

The American Society of Anesthesiologists physical status classification (ASA) was designed to assess the physical status of the patient. First published in 1941, it has remained virtually unaltered since a minor change was accepted in 1961 [54]. It is now widely used globally as a standard preoperative measurement [55]. Hence, it is readily available from medical charts. It ranks patients in five groups based on severity of diseases (Table 1).

ASA physical status has been shown to be useful in assessing risk of intra- and postoperative nonorthopedic complications [6, 56] as well as morbidity [57], mortality, cost, and length of stay [55]. The ability of ASA to predict

Table 1 ASA score

1 A normally healthy patient
2 A patient with mild systemic disease
3 A patient with severe systemic disease that limits activity but is not
incapacitating
4 A patient with an incapacitating systemic disease that is a constant
threat to life
5 A moribund patient who is not expected to survive $24 \mathrm{~h}$ with or
without treatment

1 A normally healthy patient

2 A patient with mild systemic disease

3 A patient with severe systemic disease that limits activity but is not incapacitating

threat to life

without treatment infection in total joint surgery is controversial, as some studies find an association [58, 59] whereas others do not $[60,61]$. Although the ASA might suffer from lack of precision and low reliability $[62,63]$, it has been shown to predict dislocations in total joint arthroplasty [64] as well as the need for a rehabilitation service postoperatively.

The similarities and differences between the Charlson comorbidity index and the ASA classification are elucidated in a study by Weaver et al. [65]. In this study, $78 \%$ of patients had Charlson score of 0 , and $22 \%$ had a score of 2 or worse. The proportion of patients was 3\%, 45\%, 49\%, and $3 \%$ in ASA classes 1-4. The discrepancy between the comorbidity index and the anesthesiologic risk assessment instrument is striking. Nevertheless, the main finding in the study was that preoperative comorbid conditions relate to poor outcomes after total joint arthroplasty.

Interestingly, three large arthroplasty registries in Scandinavia have chosen different ways of assessing preoperative health status. The Norwegian Joint Replacement Registry utilizes the ASA score [66], whereas the Swedish Hip Registry uses the Charnley classification [50] and the Danish Hip Arthroplasty Register makes use of the Charlson Index [34].

As the role of mental health in outcomes studies after joint replacement becomes increasingly elucidated, it seems pertinent that mental health should be regarded as a comorbidity and accounted for in a comorbidity index. Studies have shown that impaired mental health negatively affects outcome after knee as well as hip replacement [67].

\section{Selection of instruments}

There is little doubt that comorbidities are important in modulating outcome in total joint surgery. However, comorbidities constitute a wide range of conditions that might influence outcome in a variety of ways. Hypertension and diabetes mellitus are among the most frequent comorbidities. It is very hard to find any study on the impact of hypertension on outcomes in total joint surgery, whereas diabetes mellitus is a well-studied entity. It is a comorbid disease that is significantly related to complications in several diseases [9], and preoperative factors such as obesity and associated diseases may adversely affect the clinical outcome of total knee arthroplasty (TKA) as well as hip replacement in diabetic patients [68, 69].

There are multiple ways of assessing the preoperative health status of the patient. Some instruments, such as the SF-36, are generic and express the general health of the patient with any diagnosis. The SF-36 covers both physical and mental components of health and may be used for identifying specific problems that need closer follow-up, such as anxiety or depression that might benefit from closer 
follow-up by trained professionals both pre- and postoperatively. Health-related quality-of-life instruments might also be used to this end [70].

Other instruments like the WOMAC and the Hip Osteeoarthritis Outcomes Scale (HOOS) are disease-, or even joint specific. Hip and knee rating scales may be used preoperatively to obtain a baseline value, and these scales are expected to correlate well with less specific scales. Furthermore, some of the specific scales attempt to incorporate more general aspects of patient health. The Knee Society rating scale contains a scale for stratification of patients according to comorbidities that closely resembles the Charnley classification, whereas the Hip Injury and Osteoarthritis Outcomes Scale (HOOS) and Hip Injury and Osteoarthritis Outcomes Scale (KOOS) [71] incorporate elements from the WOMAC.

Both general scales and more specific rating scales may be used postoperatively in order to monitor the effect of treatment. In contrast, the comorbidity instruments are generally not expected to change following surgery. These indices express the basic health status of the patient and are modulators of the pre- and postoperative course. The ASA score is a measure of patient health with a focus on severity of disease as it relates to operative risk and is not likely to change, whereas it is known that the Charnley class of the patient may change with long-term follow-up. Activity scales express actual levels of patient activity, which may change in the event of successful surgery. Hence, they may be used as outcome measures as well.

None of these instruments is all-inclusive, and they all seem to relate various aspects of patient health status. In order to provide a complete picture it is necessary to use a combination of instruments. For routine clinical use, we recommend using the ASA as a comorbidity instrument, supplemented by an instrument that covers possible mental health issues, such as the SF-12 or the SF-36. For research purposes, we think that scientists should consider using one of the validated instruments developed specifically for orthopedic use such as the Index of Coexistent Disease (ICED) or the Functional Comorbidity Index (FCI).

\section{Conflict of interest None.}

Open Access This article is distributed under the terms of the Creative Commons Attribution Noncommercial License which permits any noncommercial use, distribution, and reproduction in any medium, provided the original author(s) and source are credited.

\section{References}

1. Elders MJ (2000) The increasing impact of arthritis on public health. J Rheumatol Suppl 60:6-8

2. Elders MJ (2008) 2008 Hip and Knee implant review. Orthopaedic network news 19:1-20
3. Peyron JG (1986) Osteoarthritis. The epidemiologic viewpoint. Clin Orthop Relat Res 213:13-19

4. Rasanen P et al (2007) Effectiveness of hip or knee replacement surgery in terms of quality-adjusted life years and costs. Acta Orthop 78:108-115

5. Feinstein A (1970) The pe-therapeutic classification of co-morbidity in chronic disease. J Chron Dis 23:455-468

6. Perka C, Arnold U, Buttgereit F (2000) Influencing factors on perioperative morbidity in knee arthroplasty. Clin Orthop Relat Res 378:183-191

7. Rius $\mathrm{C}$ et al (2004) An adaptation of Charlson comorbidity index predicted subsequent mortality in a health survey. J Clin Epidemiol 57:403-408

8. Dunbar MJ, Robertsson O, Ryd L (2004) What's all that noise? The effect of co-morbidity on health outcome questionnaire results after knee arthroplasty. Acta Orthop Scand 75:119-126

9. Gijsen R et al (2001) Causes and consequences of comorbidity: a review. J Clin Epidemiol 54:661-674

10. Shwartz M, Iezzoni LI, Moskowitz MA, Ash AS, Sawitz E (1996) The importance of comorbidities in explaining differences in patient costs. Med Care 34:767-782

11. Ethgen O, Bruyere O, Richy F, Dardennes C, Reginster JY (2004) Health-related quality of life in total hip and total knee arthroplasty. A qualitative and systematic review of the literature. J Bone Joint Surg [Am] 86-A:963-974

12. Ritter MA, Albohm MJ, Keating EM, Faris PM, Meding JB (1995) Comparative outcomes of total joint arthroplasty. J Arthroplasty 10:737-741

13. Wurtz LD, Feinberg JR, Capello WN, Meldrum R, Kay PJ (2003) Elective primary total hip arthroplasty in octogenarians. J Gerontol A Biol.Sci Med Sci 58:M468-M471

14. Barrett $\mathbf{J}$ et al (2005) Survival following total hip replacement. J Bone Joint Surg Am 87:1965-1971

15. Lie SA, Engesaeter LB, Havelin LI, Gjessing HK, Vollset SE (2000) Mortality after total hip replacement: 0-10-year follow-up of 39,543 patients in the Norwegian arthroplasty register. Acta Orthop Scand 71:19-27

16. Deyo RA, Cherkin DC, Ciol MA (1992) Adapting a clinical comorbidity index for use with ICD-9-CM administrative databases. J Clin Epidemiol 45:613-619

17. Quan H, Parsons GA, Ghali WA (2002) Validity of information on comorbidity derived rom ICD-9-CCM administrative data. Med Care 40:675-685

18. Humphries $\mathrm{KH}$ et al (2000) Co-morbidity data in outcomes research: are clinical data derived from administrative databases a reliable alternative to chart review? J Clin Epidemiol 53:343-349

19. Mont MA et al (2002) Is coding of diagnoses, comorbidities, and complications in total knee arthroplasty accurate? J Arthroplasty 17:767-772

20. Mears SC et al (2002) Coding of diagnoses, comorbidities, and complications of total hip arthroplasty. Clin.Orthop.Relat Res164-170

21. DesHarnais SI, Forthman MT, Homa-Lowry JM, Wooster LD (2000) Risk-adjusted clinical quality indicators: indices for measuring and monitoring rates of mortality, complications, and readmissions. Qual Manag Health Care 9:14-22

22. Linet MS, Harlow SD, McLaughlin JK, McCaffrey LD (1989) A comparison of interview data and medical records for previous medical conditions and surgery. J Clin Epidemiol 42:1207-1213

23. Greenfield S et al (1995) Development and testing of a new measure of case mix for use in office practice. Med Care 33:AS47-AS55

24. Katz JN, Chang LC, Sangha O, Fossel AH, Bates DW (1996) Can comorbidity be measured by questionnaire rather than medical record review? Med Care 34:73-84 
25. Sangha O, Stucki G, Liang MH, Fossel AH, Katz JN (2003) The Self-Administered Comorbidity Questionnaire: a new method to assess comorbidity for clinical and health services research. Arthritis Rheum 49:156-163

26. Black C, Roos NP (1998) Administrative data. Baby or bathwater? Med Care 36:3-5

27. Hall SF (2006) A user's guide to selecting a comorbidity index for clinical research. J Clin Epidemiol 59:849-855

28. Lin JJ, Kaplan RJ (2004) Multivariate analysis of the factors affecting duration of acute inpatient rehabilitation after hip and knee arthroplasty. Am J Phys Med Rehabil 83:344-352

29. Brinker MR, Lund PJ, Barrack RL (1997) Demographic biases of scoring instruments for the results of total knee arthroplasty. J Bone Joint Surg Am 79:858-865

30. de Groot V, Beckerman H, Lankhorst GJ, Bouter LM (2003) How to measure comorbidity. A critical review of available methods. J Clin Epidemiol 56:221-229

31. Charlson ME, Pompei P, Ales KL, MacKenzie CR (1987) A new method of classifying prognostic comorbidity in longitudinal studies: development and validation. J Chronic Dis 40:373-383

32. SooHoo NF, Lieberman JR, Ko CY, Zingmond DS (2006) Factors predicting complication rates following total knee replacement. J Bone Joint Surg Am 88:480-485

33. Reininga IH et al (2007) Effectiveness of computer-navigated minimally invasive total hip surgery compared to conventional total hip arthroplasty: design of a randomized controlled trial. BMC Musculoskelet Disord 8:4

34. Johnsen SP et al (2006) Patient-related predictors of implant failure after primary total hip replacement in the initial, short- and long-terms. A nationwide Danish follow-up study including 36, 984 patients. J Bone Joint Surg Br 88B:1303-1308

35. Kreder HK et al (2003) Provider volume and other predictors of outcome after total knee arthroplasty: a population study in Ontario. Can J Surg 46:15-22

36. Hall SF, Groome PA, Streiner DL, Rochon PA (2006) Interrater reliability of measurements of comorbid illness should be reported. J Clin Epidemiol 59:926-933

37. Fortin PR et al (1999) Outcomes of total hip and knee replacement: preoperative functional status predicts outcomes at 6 months after surgery. Arthritis Rheum 42:1722-1728

38. Harse JD, Holman CD (2005) Charlson's Index was a poor predictor of quality of life outcomes in a study of patients following joint replacement surgery. J Clin Epidemiol 58:1142-1149

39. Greenfield S, Apolone G, McNeil BJ, Cleary PD (1993) The importance of co-existent disease in the occurrence of postoperative complications and one-year recovery in patients undergoing total hip replacement. Comorbidity and outcomes after hip replacement. Med Care 31:141-154

40. Cleary PD et al (1991) Variations in length of stay and outcomes for six medical and surgical conditions in Massachusetts and California. JAMA 266:73-79

41. Groll DL, To T, Bombardier C, Wright JG (2005) The development of a comorbidity index with physical function as the outcome. J Clin Epidemiol 58:595-602

42. Groll DL, Heyland DK, Caeser M, Wright JG (2006) Assessment of long-term physical function in acute respiratory distress syndrome (ARDS) patients: comparison of the Charlson Comorbidity Index and the Functional Comorbidity Index. Am J Phys Med Rehabil 85:574-581

43. Charnley J, Halley DK (1975) Rate of wear in total hip replacement. Clin Orthop Relat Res 170-179

44. Halley DK, Charnley J (1975) Results of low friction arthroplasty in patients thirty years of age or younger. Clin Orthop Relat Res 112:180-191
45. Roder $\mathrm{C}$ et al (2006) Avoiding misclassification bias with the traditional Charnley classification: rationale for a fourth Charnley class BB. J Orthop Res 24:1803-1808

46. Soderman P, Malchau H (2001) Is the Harris hip score system useful to study the outcome of total hip replacement? Clin Orthop Relat Res 384:189-197

47. Roder C et al (2003) Demographic factors affecting long-term outcome of total hip arthroplasty. Clin Orthop Relat Res 417:62-73

48. Soderman P et al (2001) Outcome after total hip arthroplasty: part II. Disease-specific follow-up and the Swedish National Total Hip Arthroplasty Register. Acta Orthop Scand 72:113-119

49. Garellick G, Malchau H, Herberts P (1998) Specific or general health outcome measures in the evaluation of total hip replacement. A comparison between the Harris hip score and the Nottingham health profile. J Bone Joint Surg Br 80:600-606

50. Malchau H, Garellick G, Eisler T, Karrholm J, Herberts P (2005) Presidential guest address: the Swedish Hip Registry: increasing the sensitivity by patient outcome data. Clin Orthop Relat Res 441:19-29

51. Munger P, Roder C, Ckermann-Liebrich U, Busato A (2006) Patient-related risk factors leading to aseptic stem loosening in total hip arthroplasty: a case-control study of 5, 035 patients. Acta Orthop 77:567-574

52. Hozack WJ et al (1990) Survivorship analysis of 1, 041 Charnley total hip arthroplasties. J Arthroplasty 5:41-47

53. Insall JN, Dorr LD, Scott RD, Scott WN (1989) Rationale of the Knee Society clinical rating system. Clin Orthop Relat Res 13-14

54. Saklad M (1941) Grading of patients for surgical procedures. Anesthesiology 2:281-284

55. Davenport DL, Bowe EA, Henderson WG, Khuri SF, Mentzer RM Jr (2006) National Surgical Quality Improvement Program (NSQIP) risk factors can be used to validate American Society of Anesthesiologists Physical Status Classification (ASA PS) levels. Ann Surg 243:636-641

56. Cohen MM, Duncan PG (1988) Physical status score and trends in anesthetic complications. J Clin Epidemiol 41:83-90

57. Cullen DJ, Apolone G, Greenfield S, Guadagnoli E, Cleary P (1994) ASA Physical Status and age predict morbidity after three surgical procedures. Ann Surg 220:3-9

58. Ridgeway $S$ et al (2005) Infection of the surgical site after arthroplasty of the hip. J Bone Joint Surg Br 87:844-850

59. Gordon SM, Culver DH, Simmons BP, Jarvis WR (1990) Risk factors for wound infections after total knee arthroplasty. Am J Epidemiol 131:905-916

60. Peersman G, Laskin R, Davis J, Peterson MG, Richart T (2008) ASA physical status classification is not a good predictor of infection for total knee replacement and is influenced by the presence of comorbidities. Acta Orthop Belg 74:360-364

61. Patel VP et al (2007) Factors associated with prolonged wound drainage after primary total hip and knee arthroplasty. J Bone Joint Surg Am 89:33-38

62. Mak PH, Campbell RC, Irwin MG, American Society of Anesthesiologists (2002) The ASA Physical Status Classification: inter-observer consistency. American Society of Anesthesiologists. Anaesth Intensive Care 30(5):633-640

63. Ranta S, Hynynen M, Tammisto T (1997) A survey of the ASA physical status classification: significant variation in allocation among finnish anaesthesiologists. Acta Anaesthesiol Scand 41:629-632

64. Jolles BM, Zangger P, Leyvraz PF (2002) Factors predisposing to dislocation after primary total hip arthroplasty: a multivariate analysis. J Arthroplasty 17:282-288

65. Weaver F et al (2003) Preoperative risks and outcomes of hip and knee arthroplasty in the Veterans Health Administration. J Arthroplasty 18:693-708 
66. The Norwegian arthroplasty register (2007) Annual report 2007

67. Ayers DC, Franklin PD, Ploutz-Snyder R, Boisvert CB (2005) Total knee replacement outcome and coexisting physical and emotional illness. Clin Orthop Relat Res 440:157-161

68. Moon HK, Han CD, Yang IH, Cha BS (2008) Factors affecting outcome after total knee arthroplasty in patients with diabetes mellitus. Yonsei Med J 49:129-137

69. Bolognesi MP et al (2008) The impact of diabetes on perioperative patient outcomes after total hip and total knee arthroplasty in the United States. J Arthroplasty 23:92-98
70. Tellini A et al (2008) Quality of life evaluation in patients affected by osteoarthritis secondary to congenital hip dysplasia after total hip replacement. J Orthop Traumatol 9:155-158

71. Roos EM, Lohmander LS (2003) The Knee injury and Osteoarthritis Outcome Score (KOOS): from joint injury to osteoarthritis. Health Qual Life Outcomes 1:64 